\title{
Mechanical and transport properties in ternary blended self compacting concrete with metakaolin and fly ash
}

\author{
Kannan $\mathrm{V}^{1}$, Ganesan $\mathrm{K}^{2}$ \\ ${ }^{I}$ National college of engineering, Department of civil engineering, Tirunelveli, India. \\ ${ }^{2}$ Karaikudi institute of technology, Department of civil engineering, Karaikudi, India.
}

\begin{abstract}
This paper reports an experimental study carried out to investigate the influence of synergic effects of metakaolin and Fly ash on the mechanical and transport properties of self compacting concrete. The results showed that the combination of metakaolin and fly ash provides a positive effect on mechanical and transport properties of self compacting concrete. Besides, the sample incorporating the ternary blend of cement with 15\% metakaolin and $15 \%$ fly ash showed better compressive strength than that of the normal self compacting concrete without metakaolin and fly ash. This blend proved to be the optimum combination for achieving maximum synergic effect. In addition, the resistance to chloride ion penetration was directly varied with the ( $\mathrm{Si}$ $\mathrm{O}_{2}+\mathrm{Al}_{2} \mathrm{O}_{3}+\mathrm{Fe}_{2} \mathrm{O}_{3}$ )/ $\mathrm{CaO}$ ratio.
\end{abstract}

Key words: Chloride permeability; Pozzolanic materials; Self compacting concrete; Strength; Synergic effect

\section{Introduction}

In recent years, many researchers have established that the use of supplementary cementitious materials (SCMs) like blast furnace slag, silica fume, metakaolin (MK), fly ash (FA) and rice husk ash (RHA) etc. can, not only improve the various properties of concrete - both in its fresh and hardened states, but also can contribute to economy in construction costs. Amrutha et al. [1] found that the strength and durability characteristics of concrete mixes with such SCMs have to be ascertained before using them in large infrastructural projects. Permeability of concrete is believed to be the most important characteristic of concrete that affects its durability. Amrutha et al. [1] also found that the Poor impermeability of concrete may lead to the ingress of Chloride ions into concrete resulting in the corrosion of the steel rebar's embedded in it. Once this occurs, the structure will no longer maintain its structural integrity; the lifespan is reduced, and the general safety of the public amenity is severely degraded.

Ambroise $\mathrm{J}$ et al. [2] clearly demonstrated that the MK is a valuable pozzolanic, and thermally activated aluminosilicate material obtained by calcining kaolin clay within the temperature range of $700-850^{\circ} \mathrm{C}$. MK is usually added to concrete in amount of $5-15 \%$ by weight of cement. Addition of MK causes increase in mechanical strength, enhancement of long term strengths, decrease of permeability, porosity, reduction of efflorescence, increase of resistance to soluble chemicals like sulphates, chlorides and acids. Okan karahan et al. [3] suggested that the addition of MK decreases workability of fresh concrete mix. This disadvantage can be reduced by superplasticizers (SP) or increasing water to binder (W/B) ratio. However, rheological properties of fresh concrete mix depend on the type of SP. Okan karahan et al. [3] also stated that the worse workability of concrete mix caused by MK can also be adjusted by addition of FA. Higher dose of MK in concrete increases the proportion of pores with diameter up to $0.02 \mu \mathrm{m}$. At the same time, the volume of capillary pores of the size $0.05-0.1 \mu \mathrm{m}$ causing higher permeability is lower.

Fly ash is the finely divided mineral residue resulting from the combustion of ground or powdered coal in electric generating plant. Fly ash consists of inorganic matter present in the coal that has been fused during coal combustion. This material is solidified while suspended in the exhaust gases and is collected from the exhaust gases by electrostatic precipitators. Since the particles solidify while suspended in the exhaust gases, fly ash particles are generally spherical in shape. Due to its pozzolanic nature, FA is a beneficial mineral admixture for concrete. It influences many properties of concrete in both fresh and hardened state. Moreover, utilization of waste materials in cement and concrete industry reduces the environmental problems of power plants and decreases electric costs. Hassan K.E et al. [4] concluded that the two mineral admixtures, such as silica fume and fly ash are considerably influenced on the properties of super-plasticized high-performance concrete and usage of the mineral admixtures improved the properties of high performance concrete. Gopalakrishna $\mathrm{S}$ et al. [5] concluded that the addition of fly ash, compressive strength is enhanced up to $80 \mathrm{MPa}$ with $25 \%$ replacement of fly ash and also the fly ash blended concretes have superior durability properties.

Luiz Antonio Pereira de oliveira et al. [6] showed that the incorporation of pozzolanic materials as a partial replacement to ordinary Portland cement in concrete is an effective means for improving the fresh state and harden state properties. Skarendhal.A [7] concluded that the improving the fresh state and harden properties, is due to the fact that calcium hydroxide $\left(\mathrm{Ca}(\mathrm{OH})_{2}\right)$ produced by cement hydration reacts with pozzolanic 
materials like Rice Husk Ash(RHA), Metakaolin (MK), Fly Ash(FA), Silica fume etc. and produces additional calcium silicate hydrate (C-S-H) gel, blocking existing pores and altering pore structures. The formation of that gel can improve the strength and durability of concrete. In this study, the effect of MK in combination with and without FA on mechanical and permeability properties of SCC was experimentally evaluated. Furthermore the relationship between $\left(\mathrm{Si} \mathrm{O}_{2}+\mathrm{Al}_{2} \mathrm{O}_{3}+\mathrm{Fe}_{2} \mathrm{O}_{3}\right) / \mathrm{Ca} \mathrm{O}$ ratio and the resistance of chloride ion penetration on SCC were evaluated.

\subsection{Materials used}

\section{Materials and methods}

Ordinary Portland cement (OPC) conforming to Indian standard code IS 8112-1995 was used. Graded river sand passing through $1.18 \mathrm{~mm}$ sieve with fineness modulus of 2.27 and specific gravity of 2.53 was used as fine aggregate $(\mathrm{Fa})$. Locally available crushed granite aggregate, passing through $12.5 \mathrm{~mm}$ sieve while being retained on $4.75 \mathrm{~mm}$ sieve with the fineness modulus of 6.68 and specific gravity of 2.78 (conforming to IS 3831970) was used as coarse aggregate $(\mathrm{Ca})$. Commercially available MK was used for this study whereas; FA was obtained from thermal power plant, tuticorin district, tamilnadu state, India.

\subsection{Physical chemical analyses of OPC, MK and FA}

Mineralogical analysis for mean grain size and particles general forms of MK and FA were carried out by X-ray diffraction analysis. Specific surface area of OPC, MK and FA were measured as per IS 4031 (part 2)1995 using blain's air permeability apparatus. Physical properties such as specific gravity, bulk density and fineness of OPC, MK and FA were determined as per IS 4031 (parts)-1985 and IS 1727-1995. Chemical analysis for oxide composition of OPC, MK and FA were determined as per IS 4032-1985 and IS 1727-1995.

\subsection{Chemical admixtures}

Superplasticisers (SP) or high range water reducing admixtures are an essential component of SCC. Conplast SP 430 was used as superplasticiser (conforming to IS: 9103:1999).

\subsection{Blended cement}

MK and FA blended cements were prepared by replacing OPC with different amount of MK and FA (5\%, 10\%, 15\%, 20\%, 25\% and 30\% by weight of cement), Where as combination of MK and FA blended cement were prepared by replacing OPC with different amount of MK+FA with equal ratio $(10 \%, 20 \%, 30 \%$ and $40 \%$ by weight of cement). The blended cement was prepared in dry condition. The mixtures were thoroughly homogenized and kept in polythene bottles.

\subsection{Mix proportions and casting of Self compacting concrete specimens}

Numbers of attempts were made in laboratory to get optimum mix proportion to produce M30 grade SCC without segregation and bleeding with satisfying the properties both in fresh and harden states. For this study totally seventeen SCC mixes were prepared with a water to binder (W/(C+MK or FA or MK+FA) ratio of 0.55 with $2 \%$ of superplasticiser. Three types of the SCC mix were prepared and these mixes were designated as, SCCI $(05 \% \mathrm{MK}, \quad 10 \% \mathrm{MK} \ldots . .30 \% \mathrm{MK})$, SCCII $(05 \% \mathrm{FA}, \quad 10 \% \mathrm{FA} \ldots . . .30 \% \mathrm{FA})$ and $\mathrm{SCCIII}$ $(05 \% \mathrm{MK}+05 \% \mathrm{FA}, 10 \% \mathrm{MK}+10 \% \mathrm{FA} . .20 \% \mathrm{MK}+20 \% \mathrm{FA})$. The mix proportions are presented in Table 1.

The SCC was mixed for 5 minutes in laboratory drum mixer. For all mixes, nine cube specimens of $100 \mathrm{~mm}$ size were cast from each mix for compressive strength testing. Three cylindrical specimens of $150 \mathrm{~mm}$ diameter and $300 \mathrm{~mm}$ height were also cast from each mix for determining the splitting tensile strength. Nine cylindrical specimens of $100 \mathrm{~mm}$ diameter and $50 \mathrm{~mm}$ height were cast from each mix for transport properties tests and it consists of water absorption test, Coefficient of water absorption test and Rapid chloride test. Before compression test, all specimens were tried and used for ultrasonic pulse velocity test. After casting, all the specimens were left covered in the casting room for 24 hours. The specimens were demoulded and transferred to moist curing room until the time of testing.

\subsection{Fresh state properties of SCC}

Slump flow, V-funnel at 5 minutes, L-box tests were performed in the laboratory according to EFNARC specifications on fresh SCC mixes to find filling ability, passing ability and segregation resistance. The fresh state properties of SCC mixes are shown in Table 2.

\subsection{Compressive strength of SCC}

Compressive strength of MK, FA and combination of MK and FA blended cement SCC cube was determined as per IS 9013-1997 after 7, 28 and 90 days of moisture curing.

\subsection{Splitting tensile strength of SCC}


Splitting tensile strength test was conducted on MK, FA and combination of MK and FA blended SCC cylinder as per IS 5816-1999 after 28 days of moisture curing.

\subsection{Ultrasonic pulse velocity}

The UPV of MK, FA and combination of MK and FA blended SCC specimens were determined as per IS 13311(part1)-1992 after 28 days of moisture curing.

\subsection{Dynamic modulus of elasticity}

The dynamic modulus of elasticity of MK, FA and combination of MK and FA blended SCC specimens were calculated according to IS 13311(part1)-1992 after 28 days moisture curing and according to IS 13311(part-1)-1992, the dynamic Poisson's ratio varies from 0.20 to 0.35 , with 0.24 as average. In this study Poisson's ratio $(\mu)$ is taken as 0.24 .

\subsection{Saturated water absorption}

Percentage of water absorption is measures of the pore volume or porosity in harden concrete, which is occupied by water in saturated condition. Saturated water absorption values of MK, FA and combination of MK and FA blended SCC specimens were measured as per ASTM C 642 after 28 days of moisture curing.

\subsection{Coefficient of water absorption}

Coefficient of water absorption is suggested as a measure of permeability of water. This is measured by the rate of up take of water by dry concrete in a period of one hour. The SCC specimens were preconditioned by drying the specimens in an oven at $105^{\circ} \mathrm{C}$ for 7 days until constant weight was reached and then allowed to cool in a sealed container for three days. The sides of the specimen were sealed with transparent epoxy coating so as the water to penetrate the circular cross section. Then the samples were dipped in the water in a vertical position with one open surface in partially immersed to depth of $5 \mathrm{~mm}$ and the other with the laboratory air as shown in Fig. 1. The quantity of water absorbed during the first 60 minutes was calculated. Coefficient of water absorption values of MK, FA and combination of MK and FA blended SCC specimens after 28 days of water curing were determined by the following equation 1 ,

$$
K a=[Q / A]^{2} x[1 / t]
$$

Where $\boldsymbol{K} \boldsymbol{a}$ is coefficient of water absorption $\left(\mathrm{m}^{2} / \mathrm{s}\right), \boldsymbol{Q}$ is quantity of water absorbed $\left(\mathrm{m}^{3}\right)$ by the oven dry specimen in time (t), $\boldsymbol{t}$ is $3600 \mathrm{~s}$ and $\boldsymbol{A}$ is total surface area $\left(\mathrm{m}^{2}\right)$ of SCC specimen through which water penetrates.

\subsection{Chloride penetration}

The resistance to chloride ion penetration in terms of total charge passed in coulombs was measured as per ASTM C 1202 for MK, FA and combination of MK and FA blended SCC specimens after 28 days of moisture curing. The positive reservoir of the cell was filled with $0.3 \mathrm{M} \mathrm{NaOH}$ solution, while the negative reservoir was filled with $3 \% \mathrm{NaCl}$ solution as shown in Fig. 2. A DC potential of $60 \mathrm{~V}$ was applied across the specimen faces, and the current was recorded every 30 minute intervals, covering a total period of 6 hours. By knowing the current and time history, the total charge (coulombs) passed through the specimen was computed by the following equation 2 , based on trapezoidal rule.

$$
Q=\left(I_{0}+2 I_{30}+2 I_{60}+\cdots \cdot+2 I_{300}+2 I_{330}+I_{360}\right)
$$

Where $\boldsymbol{Q}$ is the charge passed (coulombs); $\boldsymbol{I}_{\boldsymbol{0}}$ is the current (amperes) immediately after voltage is applied; $\boldsymbol{I}_{t=30 \text {, }}$ ${ }_{60,360}$ is the current (amperes) at time after voltage applied.

\section{Results and discussion}

\subsection{Physical and chemical analyses of OPC, MK and FA}

The physical properties of OPC, MK and FA are presented in Table 3 and compared with MK and FA from other references including the work of wild and khatib [20] Poon et al. [18] Justice and Kurtis [19] and A.K. Parande et al. [21]. The X-ray diffraction (XRD) pattern of the MK and FA used in this study shown in fig. 3 and 4, showing high amount of quartz phase of MK with amorphous form and silica phase of FA with crystalline form. In addition, the mean particle size was also determined by XRD analysis. The density, specific gravity and mean grain size of MK and FA are found to be less than those of OPC.

Chemical composition data for OPC, MK and FA are compared in Table 4. This particular MK consists $51.80 \%$ of silica, $43.75 \%$ of alumina and FA consists of $58.35 \%$ of silica. The loss of ignition value for MK and FA are $0.34 \%, 3.45 \%$ respectively. 


\subsection{Compressive strength of SCC}

The compressive strength of MK, FA and their combination blended SCC specimen are shown in Table 5. According to results SCC with MK and combination of MK and FA show higher compressive strength than normal SCC (SCC with 0\% replacement of cement). It is interesting to see that the compressive strength of SCC with 15\% FA was higher than that of the normal SCC. The compressive strength of SCC decreases when the amount of cement replacement by FA is higher than $20 \%$. It may be due to the fact of increasing the workability properties of the SCC with FA. This result shows the benefit of using FA in combination with MK to produce SCC with higher replacement of cement about 40\% (20\% MK + 20\% FA).

Comparison of the data for 7, 28 and 90 days of curing time shows that the compressive strength increases with MK up to $20 \%$, FA up to $15 \%$ and combination of MK and FA up to $30 \%$.

\subsection{Splitting tensile strength of SCC}

The splitting tensile strength of MK, FA and combination of MK and FA blended SCC after 28 days curing are shown in Fig. 5 and 6. It can be clearly seen that the splitting tensile strength value increases with MK content up to $20 \%$, FA content up to $15 \%$ and combination of MK and FA up to $40 \%$, and then at $30 \%$ MK, the splitting tensile strength is higher than the normal SCC. But at 30\% FA, the splitting tensile strength is lower than the Normal SCC.

\subsection{Ultrasonic pulse velocity}

The UPV values calculated for MK, FA and combination of MK and FA blended SCC's specimens after 28 days moisture curing is presented in Table 6 . It can be seen that the UPV increased with increasing percentage of MK up to 20\%, FA up to $20 \%$ and combination of MK and FA up to 30\%. At 30\% MK and $40 \%$ combination of MK and FA, there is a decrease in UPV and these values are also higher than that of normal SCC. At $25 \%$ FA there is decrease in UPV and this value is higher than of normal SCC, but there after decreased.

\subsection{Dynamic modulus of elasticity}

The dynamic modulus of elasticity (DME) values calculated for MK, FA and combination of MK and FA blended SCC's specimens after 28 days moisture curing is presented in Table 6. It can be seen that the DME increased with increasing percentage of MK up to $20 \%$, FA up to $20 \%$ and combination of MK and FA up to $30 \%$. The relationship between DME and compressive strength of combination of MK and FA blended SCC is shown in Fig. 7; it is called scattering diagram and present the positive correlation between dynamic modulus of elasticity and compressive strength. From Fig. 7, it is evident that the DME increases linearly with compressive strength values and the value of correlation coefficients indicating fairly good linear correlation between DME and compressive strength of combination of MK and FA blended SCC.

\subsection{Saturated water absorption}

Water permeability property as indicated by saturated water absorption of MK, FA and combination of MK and FA blended SCC specimen after 28 days of curing is given in Table 7. It can be seen that the percentage of water absorption decreasing with increasing of MK content up to 30\%, FA content up to $25 \%$ and combination of MK and FA content up to 40\%. MK and combination of MK and FA show the better results these are due to the fact that MK is finer than OPC and producing of an additional calcium silicate hydrate (C-S$\mathrm{H})$ gel, blocking existing pores and altering pore structures.

\subsection{Coefficient of water absorption}

Coefficient of water absorption of MK, FA and combination of MK and FA blended SCC specimen after 28 days of curing is given in Table 7. It can be seen that at 28 days of curing, coefficient of water absorption progressively decrease with increase in MK content up to $20 \%$, FA content up to $20 \%$ and combination of MK and FA content up to $40 \%$. At $30 \%$ MK, there is an increase in coefficient of water absorption and these values are also lower than that of normal SCC. At 30\% FA, the coefficient of water absorption value in increased compared to that of normal SCC.

\subsection{Chloride penetration}

The Rapid chloride permeability test results for MK, FA and combination of MK and FA blended SCC specimens are shown in Fig. 8 and 9. It can be seen that the total charge (coulombs) passing through MK, FA and combination of MK and FA blended SCC specimens continuously decreases with increase in MK, FA and combination of MK and FA contents up to $30 \%$ of MK, $25 \%$ of FA, $40 \%$ of combination of MK and FA respectively. It is also observed that the chloride permeability is considerably reduced by partial replacement of OPC with MK and combination of MK and FA. Particularly the total charge passed value for 30\% MK and $40 \%$ combination of MK and FA blended SCC is considerably less about $98.10 \%, 97.47 \%$ respectively at the age of 
Mechanical and transport properties in ternary blended self compacting concrete with metakaolin and fly ash

28 days. Further to quantify the type and nature of interdependence among the total charge passed and $\left(\mathrm{Si} \mathrm{O}_{2}+\right.$ $\left.\mathrm{Al}_{2} \mathrm{O}_{3}+\mathrm{Fe}_{2} \mathrm{O}_{3}\right) / \mathrm{CaO}$ ratio, the total charge passed is plotted against $\left(\mathrm{Si} \mathrm{O}+\mathrm{Al}_{2} \mathrm{O}_{3}+\mathrm{Fe}_{2} \mathrm{O}_{3}\right) / \mathrm{Ca} \mathrm{O}$ ratio. Fig. 10, 11 and 12 shows test results of the relationship between chemical composition and total charge passed derived from RCPT of blended SCC. It was found that the chemical compositions in each concrete mix proportion are an important factor for the permeability properties of SCC. The SCC with the $\left(\mathrm{Si} \mathrm{O}_{2}+\mathrm{Al}_{2} \mathrm{O}_{3}+\right.$ $\mathrm{Fe}_{2} \mathrm{O}_{3}$ ) / Ca O ratio of 1.1, 0.92 and 1.42, in which $30 \%$ of MK, $20 \%$ of FA and $40 \%$ of combination of MK and FA blended SCC, yielded lower value of total charge passed derived from RCPT. This is due to the amount of $\mathrm{CaO}$ and $\mathrm{SiO}_{2}$ available for optimizing the pozzolanic reaction in cement paste of each mixture contributing to the chloride permeability of SCC.

\section{FIGURES}

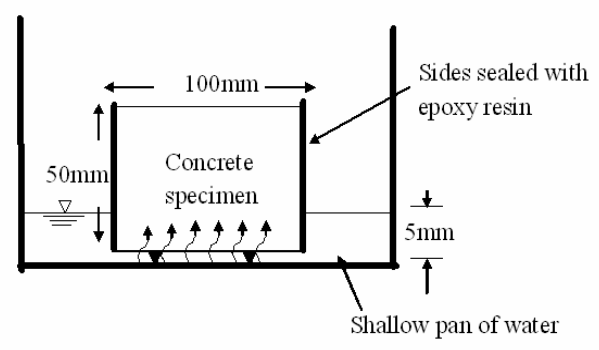

Fig. 1 Coefficient of water absorption test

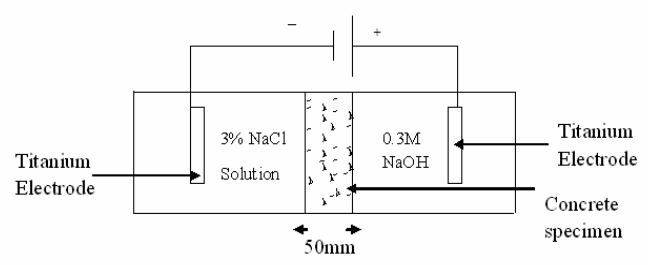

Fig. 2 Rapid chloride permeability tests

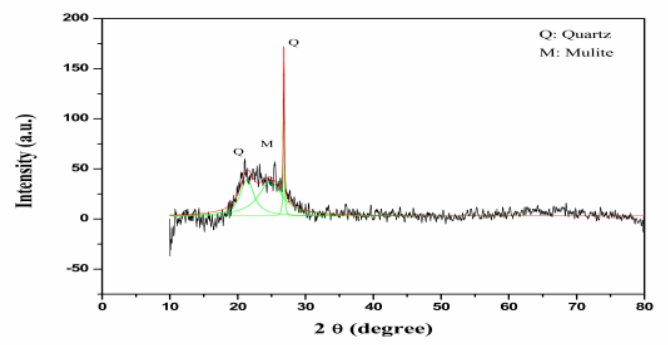

Fig. 3 X-ray diffraction (XRD) pattern for metakaolin

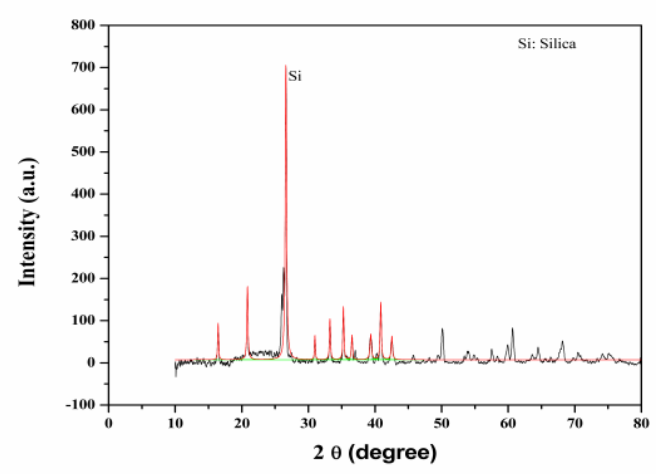

Fig. 4 X-ray diffraction (XRD) pattern for fly ash 


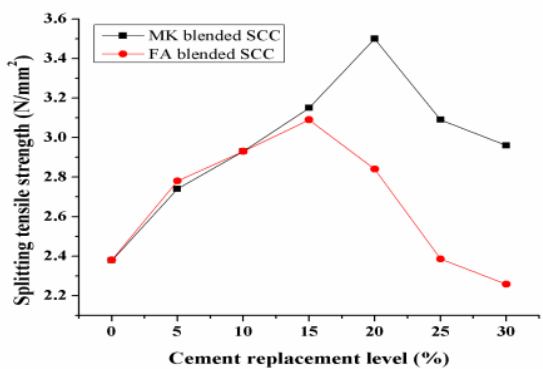

Fig. 5 Splitting tensile strength of MK and FA blended SCC

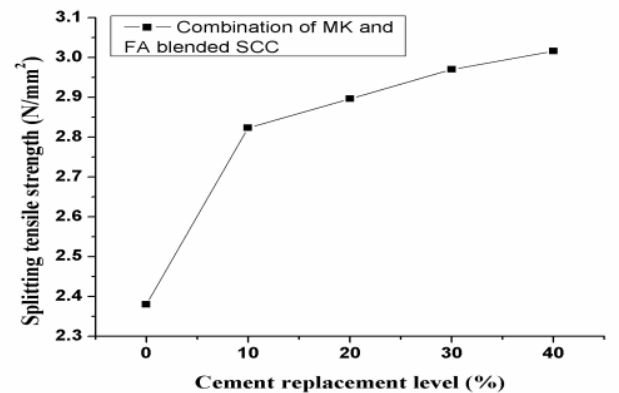

Fig. 6 Splitting tensile strength of combination of MK and FA blended SCC

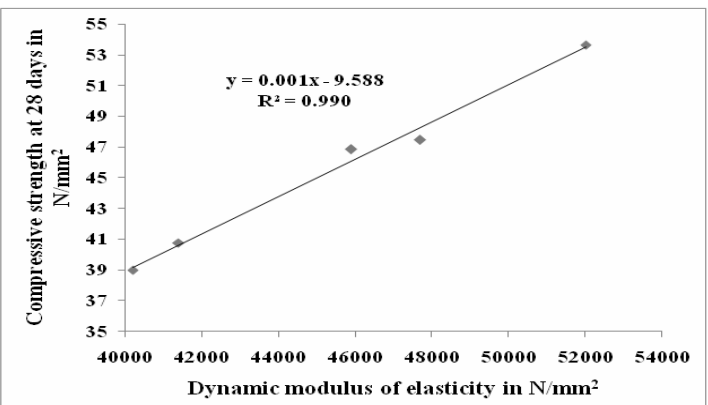

Fig. 7 Correlation between dynamic modulus of elasticity and compressive strength of combination of MK and FA blended SCC

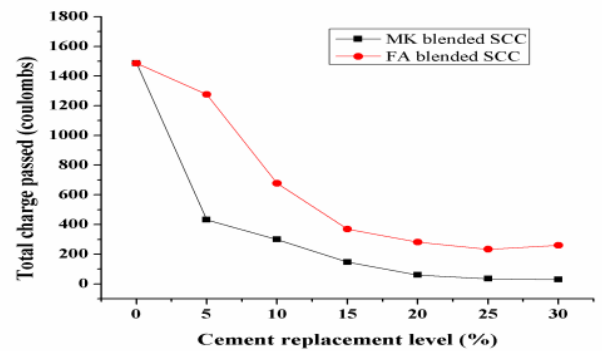

Fig. 8 Chloride permeability of MK and FA blended SCC

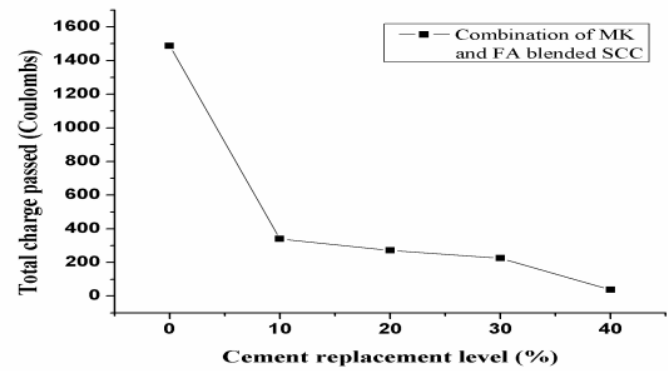


Mechanical and transport properties in ternary blended self compacting concrete with metakaolin and fly ash

Fig. 9 Chloride permeability of combination of MK and FA blended SCC

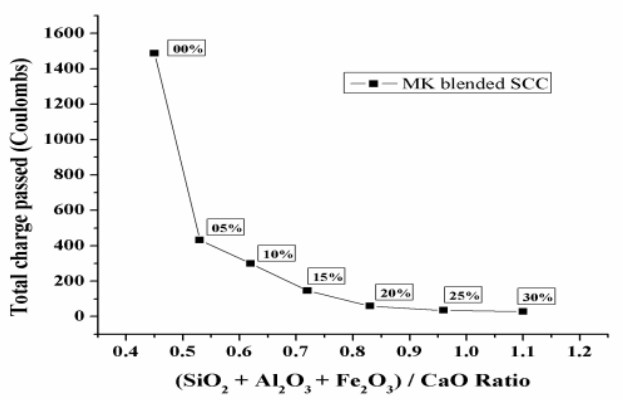

Fig. 10 Relationship between $\left(\mathrm{Si} \mathrm{O}_{2}+\mathrm{Al}_{2} \mathrm{O}_{3}+\mathrm{Fe}_{2} \mathrm{O}_{3}\right) / \mathrm{Ca} \mathrm{O}$ ratio and total charge passed of $\mathrm{MK}$ blended $\mathrm{SCC}$

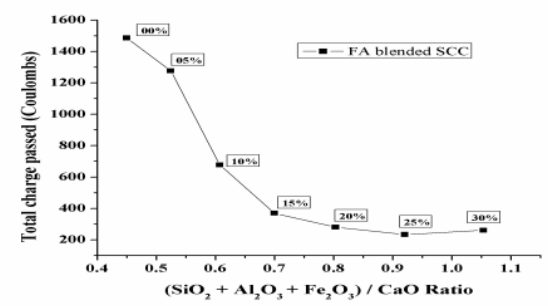

Fig. 11 Relationship between $\left(\mathrm{Si} \mathrm{O}_{2}+\mathrm{Al}_{2} \mathrm{O}_{3}+\mathrm{Fe}_{2} \mathrm{O}_{3}\right) / \mathrm{Ca} \mathrm{O}$ ratio and total charge passed of FA blended SCC

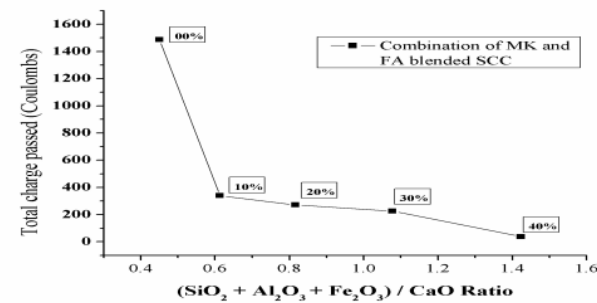

Fig. 12 Relationship between $\left(\mathrm{Si} \mathrm{O}_{2}+\mathrm{Al}_{2} \mathrm{O}_{3}+\mathrm{Fe}_{2} \mathrm{O}_{3}\right) / \mathrm{Ca} \mathrm{O}$ ratio and total charge passed of combination of $\mathrm{MK}$ and FA blended SCC

V.

TABLES

Table 1 Mix proportions of MK, FA and combination of MK and FA blended SCC

\begin{tabular}{|c|c|c|c|c|c|c|c|c|c|}
\hline \multirow{2}{*}{ Mix designation } & \multirow{2}{*}{$\begin{array}{c}\text { MK/FA/ } \\
\text { MK+FA in }\end{array}$} & \multirow{2}{*}{ W/B } & \multicolumn{9}{|c|}{ Quantities $\left(\mathrm{kg} / \mathrm{m}^{3}\right)$} \\
\cline { 5 - 10 } & & & Water & OPC & MK & FA & SP & $F a$ & $C a$ \\
\hline SCC(100\% OPC) & 0 & 0.55 & 220 & 400 & 0 & - & 8 & 880 & 800 \\
\hline SCCI-05MK & 5 & 0.55 & 220 & 380 & 20 & - & 8 & 880 & 800 \\
\hline SCCI-10MK & 10 & 0.55 & 220 & 360 & 40 & - & 8 & 880 & 800 \\
\hline SCCI-15MK & 15 & 0.55 & 220 & 340 & 60 & - & 8 & 880 & 800 \\
\hline SCCI-20MK & 20 & 0.55 & 220 & 320 & 80 & - & 8 & 880 & 800 \\
\hline SCCI-25MK & 25 & 0.55 & 220 & 300 & 100 & - & 8 & 880 & 800 \\
\hline SCCI-30MK & 30 & 0.55 & 220 & 280 & 120 & - & 8 & 880 & 800 \\
\hline SCCII-05FA & 5 & 0.55 & 220 & 380 & - & 20 & 8 & 880 & 800 \\
\hline SCCII-10FA & 10 & 0.55 & 220 & 360 & - & 40 & 8 & 880 & 800 \\
\hline SCCII-15FA & 15 & 0.55 & 220 & 340 & - & 60 & 8 & 880 & 800 \\
\hline SCCII-20FA & 20 & 0.55 & 220 & 320 & - & 80 & 8 & 880 & 800 \\
\hline SCCII-25FA & 25 & 0.55 & 220 & 300 & - & 100 & 8 & 880 & 800 \\
\hline SCCII-30FA & 30 & 0.55 & 220 & 280 & - & 120 & 8 & 880 & 800 \\
\hline SCCIII-05MK+05FA & 10 & 0.55 & 220 & 360 & 20 & 20 & 8 & 880 & 800 \\
\hline SCCIII-10MK+10FA & 20 & 0.55 & 220 & 320 & 40 & 20 & 8 & 880 & 800 \\
\hline SCCIII-15MK+15FA & 30 & 0.55 & 220 & 280 & 60 & 60 & 8 & 880 & 800 \\
\hline SCCIII-20MK+20FA & 40 & 0.55 & 220 & 240 & 80 & 80 & 8 & 880 & 800 \\
\hline
\end{tabular}


Mechanical and transport properties in ternary blended self compacting concrete with metakaolin and fly ash

Table 2 Fresh state properties of MK, FA and combination of MK and FA blended SCC

\begin{tabular}{|c|c|c|c|}
\hline \multirow{2}{*}{ Mix designation } & Slump flow in mm & $\begin{array}{c}\text { V-Funnel at 5minutes }\left(\mathrm{T}_{5 \text { min }} \text { in }\right. \\
\text { sec }\end{array}$ & L-box test, $\mathrm{H}_{2} / \mathrm{H}_{1}$ \\
\hline SCC(100\% OPC) & 740 & 3.9 & 0.94 \\
\hline SCCI-05MK & 735 & 4.2 & 0.9 \\
\hline SCCI-10MK & 710 & 4.9 & 0.85 \\
\hline SCCI-15MK & 690 & 5.8 & 0.82 \\
\hline SCCI-20MK & 678 & 6.3 & 0.74 \\
\hline SCCI-25MK & 656 & 7.2 & 0.63 \\
\hline SCCI-30MK & 610 & 7.9 & Struck \\
\hline SCCII-05FA & 725 & 6 & 0.9 \\
\hline SCCII-10FA & 740 & 6 & 0.93 \\
\hline SCCII-15FA & 768 & 5 & 0.96 \\
\hline SCCII-20FA & 785 & 5 & 1 \\
\hline SCCII-25FA & 786 & 4 & 1 \\
\hline SCCII-30FA & 824 & 4 & 0.91 \\
\hline SCCIII-05MK+05FA & 720 & 4.2 & 0.85 \\
\hline SCCIII-10MK+10FA & 710 & 5 & 0.79 \\
\hline SCCIII-15MK+15FA & 695 & 6 & 0.71 \\
\hline SCCIII-20MK+20FA & 640 & 6 & 1 \\
\hline
\end{tabular}

Table 3 Physical properties of OPC, MK and FA

\begin{tabular}{|c|c|c|c|c|c|c|}
\hline \multirow{2}{*}{ Materials } & \multicolumn{2}{|c|}{$\begin{array}{c}\text { Bulk density in } \\
\mathrm{Kg} / \mathrm{m}^{3}\end{array}$} & \multirow{2}{*}{$\begin{array}{c}\text { Specific } \\
\text { gravity }\end{array}$} & \multirow{2}{*}{$\begin{array}{c}\text { Fineness } \\
\text { passing } \\
\text { 45Micron sieve }\end{array}$} & Specific surface Area & \multirow{2}{*}{$\begin{array}{c}\text { Mean grain size in } \\
\end{array}$} \\
& loose & Dense & & & Blain's in $\mathrm{m}^{2} / \mathrm{kg}$ & \\
\hline OPC & 1.18 & 1.27 & 3.13 & 86 & 318 & 23.4 \\
\hline MK & 0.50 & 0.52 & 2.58 & 99 & 2350 & 2.93 \\
\hline FA & 0.94 & 1.20 & 2.10 & 95 & 400 & 2.88 \\
\hline
\end{tabular}

Table 4 Chemical composition of OPC, MK and FA (\%)

\begin{tabular}{|c|c|c|c|c|c|c|c|c|}
\hline Material & $\mathrm{Si} \mathrm{O}_{2}$ & $\mathrm{Al}_{2} \mathrm{O}_{3}$ & $\mathrm{Fe}_{2} \mathrm{O}_{3}$ & $\mathrm{CaO}$ & $\mathrm{Mg} \mathrm{O}$ & $\mathrm{Na}_{2} \mathrm{O}$ & $\mathrm{K}_{2} \mathrm{O}$ & $\begin{array}{c}\text { Loss on } \\
\text { ignition }\end{array}$ \\
\hline OPC & 20.25 & 5.04 & 3.16 & 63.31 & 4.20 & 0.08 & 0.51 & 3.08 \\
\hline $\mathrm{MK}$ & 51.80 & 43.75 & 0.82 & 0.09 & 0.03 & 0.07 & 0.02 & 0.34 \\
\hline FA & 58.35 & 27.6 & 4.82 & 1.45 & 1.8 & 2.46 & 1.53 & 3.45 \\
\hline
\end{tabular}

Table 5 Compressive strength of MK, FA and combination of MK and FA blended SCC

\begin{tabular}{|c|c|c|c|c|}
\hline \multirow{2}{*}{ Mix designation } & MK/FA/ MK+FA & \multicolumn{3}{|c|}{ Compressive strength (MPa) } \\
\cline { 3 - 5 } & $(\%)$ & Seven days & 28 days & 90 days \\
\hline SCC(100\% OPC) & 0 & 35.43 & 40.77 & 43.8 \\
\hline SCCI-05MK & 5 & 38.72 & 48.28 & 50.60 \\
\hline SCCI-10MK & 10 & 42.12 & 51.91 & 53.00 \\
\hline SCCI-15MK & 15 & 44.59 & 54.53 & 55.90 \\
\hline SCCI-20MK & 20 & 44.01 & 57.17 & 58.40 \\
\hline SCCI-25MK & 25 & 41.41 & 53.74 & 55.20 \\
\hline SCCI-30MK & 30 & 40.03 & 51.40 & 52.80 \\
\hline SCCII-05FA & 5 & 32.12 & 42.66 & 48.11 \\
\hline SCCII-10FA & 10 & 35.37 & 44.24 & 49.76 \\
\hline SCCII-15FA & 15 & 34.68 & 48.98 & 52.47 \\
\hline SCCII-20FA & 20 & 28.17 & 46.45 & 49.10 \\
\hline SCCII-25FA & 25 & 26.33 & 40.22 & 45.56 \\
\hline SCCII-30FA & 30 & 25.00 & 39.43 & 43.71 \\
\hline SCCIII-05MK+05FA & 10 & 38.95 & 46.84 & 48.04 \\
\hline SCCIII-10MK+10FA & 20 & 41.30 & 47.45 & 49.12 \\
\hline SCCIII-15MK+15FA & 30 & 42.63 & 53.67 & 56.34 \\
\hline SCCIII-20MK+20FA & 40 & 33.12 & 39.00 & 41.66 \\
\hline
\end{tabular}


Mechanical and transport properties in ternary blended self compacting concrete with metakaolin and fly ash

Table 6 UPV and DME of MK, FA and Combination of MK and FA blended SCC

\begin{tabular}{|c|c|c|c|c|}
\hline Mix designation & $\begin{array}{c}\mathrm{MK} / \mathrm{FA} / \\
\mathrm{MK}+\mathrm{FA}(\%)\end{array}$ & $\mathrm{UPV}(\mathrm{m} / \mathrm{sec})$ & $\begin{array}{c}\text { Category of UPV values } \\
\text { as per IS 13311(part1)- } \\
1992\end{array}$ & $\begin{array}{l}\text { Dynamic modulus of } \\
\text { elasticity in } \mathrm{N} / \mathrm{mm}^{2}\end{array}$ \\
\hline $\mathrm{SCC}(100 \%$ OPC $)$ & 0 & 4494.38 & Good & 41400 \\
\hline SCCI-05MK & 5 & 4676.54 & Excellent & 44900 \\
\hline SCCI-10MK & 10 & 4975.12 & Excellent & 50900 \\
\hline SCCI-15MK & 15 & 5025.13 & Excellent & 52300 \\
\hline SCCI-20MK & 20 & 5208.33 & Excellent & 56200 \\
\hline SCCI-25MK & 25 & 5012.53 & Excellent & 52000 \\
\hline SCCI-30MK & 30 & 4739.34 & Excellent & 46700 \\
\hline SCCII-05FA & 5 & 4594.18 & Excellent & 36800 \\
\hline SCCII-10FA & 10 & 4646.84 & Excellent & 42100 \\
\hline SCCII-15FA & 15 & 4658.39 & Excellent & 44800 \\
\hline SCCII-20FA & 20 & 4687.50 & Excellent & 47900 \\
\hline SCCII-25FA & 25 & 4502.12 & Excellent & 44700 \\
\hline SCCII-30FA & 30 & 4436.78 & Good & 44100 \\
\hline SCCIII-05MK+05FA & 10 & 4734.84 & Excellent & 45900 \\
\hline SCCIII-10MK+10FA & 20 & 4796.16 & Excellent & 47700 \\
\hline SCCIII-15MK+15FA & 30 & 4972.65 & Excellent & 52000 \\
\hline SCCIII-20MK+20FA & 40 & 4761.90 & Excellent & 45400 \\
\hline
\end{tabular}

Table 7 Permeability related properties of MK, FA and combination of MK and FA blended SCC

\begin{tabular}{|c|c|c|c|}
\hline Mix designation & $\begin{array}{c}\text { MK/FA/ MK+FA } \\
(\%)\end{array}$ & $\begin{array}{c}\text { Saturated water } \\
\text { absorption }(\%)\end{array}$ & $\begin{array}{c}\text { Coefficient of water absorption x } 10^{-10} \\
\left(\mathrm{~m}^{2} / \mathrm{s}\right)\end{array}$ \\
\hline SCC $(100 \%$ OPC) & 0 & 4.54 & 4.07 \\
\hline SCCI-05MK & 5 & 3.59 & 1.9 \\
\hline SCCI-10MK & 10 & 3.57 & 1.36 \\
\hline SCCI-15MK & 15 & 3.48 & 1.13 \\
\hline SCCI-20MK & 20 & 2.88 & 1.36 \\
\hline SCCI-25MK & 25 & 2.83 & 1.62 \\
\hline SCCI-30MK & 30 & 2.78 & 6.49 \\
\hline SCCII-05FA & 5 & 5.8 & 3.51 \\
\hline SCCII-10FA & 10 & 4.5 & 2.54 \\
\hline SCCII-15FA & 15 & 4.41 & 3.65 \\
\hline SCCII-20FA & 20 & 4.28 & 4.10 \\
\hline SCCII-25FA & 25 & 4.04 & 2.54 \\
\hline SCCII-30FA & 30 & 4.19 & 2.10 \\
\hline SCCIII-05MK+05FA & 10 & 3.51 & 1.90 \\
\hline SCCIII-10MK+10FA & 20 & 3.49 & 1.54 \\
\hline SCCIII-15MK+15FA & 30 & 3.45 & 3.38 \\
\hline SCCIII-20MK+20FA & 40 & & \\
\hline
\end{tabular}

\section{Conclusion}

Based on the experimental studies presented in this paper, the following conclusions may be drawn,

(1) Replacement with $30 \%$ of metakaolin leads to substantial improvement in strength and transport properties of blended SCC when compared to that of unblended SCC, namely,

(a) About $26 \%$ increased in compressive strength.

(b) About $38.76 \%$ decreased in water permeability.

(c) About $98.10 \%$ decreased in chloride penetration.

(2) When metakaolin which has a lower loss on ignition value compared to OPC is used to partially replace OPC, resistance to water permeability is substantially improved. This is due to the fact that MK is finer than OPC and producing of an additional calcium silicate hydrate $(\mathrm{C}-\mathrm{S}-\mathrm{H})$ gel, blocking existing pores and altering pore structures.

(4) FA can be considered as a supplementary cementitious material using for SCC, but the addition does not significantly improve the mechanical and transport properties compared to that of MK, when increasing the replacement level about $30 \%$. 
Mechanical and transport properties in ternary blended self compacting concrete with metakaolin and fly ash

(5) The combination of MK and FA can increase the total replacement level up to $40 \%$ to produce SCC without any adverse effect on strength and transport properties.

(6) There is a good synergic effect between MK and FA on the mechanical and transport properties of SCC and the resistance to chloride ion penetration of SCC is directly varied with the $\left(\mathrm{Si} \mathrm{O}_{2}+\mathrm{Al}_{2} \mathrm{O}_{3}+\mathrm{Fe}_{2} \mathrm{O}_{3}\right) / \mathrm{CaO}$ ratio.

\section{Acknowledgement}

We thank Dr.E.Kumar for his assistance with the manuscript preparation and XRD analysis. Also we thank The Principal, Government College of Engineering, Tirunelveli for providing the laboratory facilities to us to carry out the research work.

\section{References}

[1] Amrutha, Gopinatha Nayak, Mattur C. Narasimhan and Rajeeva S.V. "Chloride-Ion Impermeability of Self-Compacting HighVolume Fly Ash Concrete Mixes". International Journal of Civil \& Environmental Engineering IJCEE-IJENS, 11(4), 2009, 29- 35

[2] Ambroise J, Maximillen S, Pera J. Properties of metakaolin blended cements. Advanced Cement Materials, 1(4), 1994, 161-168.

[3] Okan karahan, Khandaker M.A hossain, Erdogan Ozbay, Mohamed Lachemi, Emre sancak. Effect of metakaolin content on the properties self- compacting light weight concrete. Construction and building materials, 31, 2012, 320-325.

[4] Hassan, K.E., Cabrera, J.G., and Maliehe, R.S. The Effect of Mineral Admixtures on the Properties of High-Performance Concrete. Cement \& Concrete Composites, 22, 2000, 267-271.

[5] Gopalakrishna S., Rajamane N.P., Neelamegam M., Peter, J.A. and Dattatreya, J.K. Effect of partial replacement of cement with fly ash on the strength and durability of HPC. The Indian Concrete Journal, 2001, 335-341.

[6] Luiz Antonio Pereira de oliveira, Joao Paulo de castro gomes, Cristiana nadir gonilho Pereira. Study of sorptivity of selfcompacting concrete with mineral additives. Journal of civil engineering and management. 9, 2006, 215-220.

[7] Goh, Chia-Chia., Show, Kuan-Yeow and Cheong, Hee-Kiat. Municipal Solid Waste Fly Ash as a Blended Cement Material. Journal of Materials in Civil Engineering, 15, 2003, 513-53-23.

[8] Skarendhal.A. "Early age and hardened properties in self compacting concrete" state-of-art report of rilem technical committee 174SCC, rilem publications. 2000, 43-46.

[9] EFNARC, specification and guidelines for self compacting concrete. Association house, UK, Feb 2002

[10] Wang, Shuxin and Li, Victor C. Engineered Cementitious Composites with High-Volume Fly Ash. Materials Journal of ACI, 104 (3), 2007, 233-241.

[11] Sabir BB, Wild S, Khatib JM. on the workability and strength development of metakaolin concrete. In: Dhir RK, Dyer TD, editors. Concrete for Environmental Enhancement and Protection. London, UK: E\&FN Spon, 1996, 651-656.

[12] Aziz, M.A.E., Aleem, S.A.E., Heikal, M. Didamony H.E. Hydration and durability of sulphate-resisting and slag cement blends in Caron's Lake water. Cement and Concrete Research. vol. 35(8), 2005, 1592- 1600.

[13] Okan karahan, Khandaker M.A hossain, Erdogan Ozbay, Mohamed Lachemi, Emre sancak. Effect of metakaolin content on the properties self- compacting light weight concrete. Construction and building materials. 31, 2012, 320-325.

[14] Kazim Turk., Sinan Caliskan and Salih Yazicioglu. Capillary water absorption of self-compacting concrete under different curing conditions. Indian journal of Engineering \& Materials Sciences, 14, 2007, 365-372.

[15] Isaia, G.C., Gastaldini, A.L.G., Moraes, R. Physical and pozzolanic action of mineral additions on the mechanical strength of highperformance concrete. Cement and Concrete Composites. vol. 25(1), 2003, 69-76.

[16] Ozawa, K., Maekawa, K., and Okamura, H. "Development of High Performance Concrete" Journal of the Faculty of Engineering, The University of Tokyo (B), XLI (3), 2001, 381-439.

[17] Sonebi , M. , Grünewald, S., and Walraven, J. "Filling Ability and Passing ability of Self Consolidating Concrete". ACI Materials Journal. 104, (2), 2007, 162-170.

[18] Yahia A, Tanimura M, Shimabukuro A, Shimoyama Y. Effect of rheological parameters on self compactability of concrete containing various mineral admixtures, Proceedings of the First RILEM International Symposium on Self- Compacting Concrete. 1999, 523-535. 